Ester Jordana Lluch

Escola Massana

Universidad Autónoma de Barcelona

\title{
La inservidumbre de la escritura en la época de la técnica: Heidegger, Nietzsche, Benjamin y Foucault.
}

\section{The in-servitude of Writing in the Age of Technique: Heidegger, Nietzsche, Benjamin and Foucault.}

\section{Resumen}

El presente artículo examina las relaciones entre escritura, técnica y pensamiento. Las reflexiones de Martin Heidegger en torno a porqué la ciencia no piensa nos permiten abordar el problema de la homogenización del pensamiento y de la escritura en las universidades contemporáneas. Afirmar hoy que «la academia no piensa» invita a una reflexión respecto a esos modos de pensamiento y escritura imperantes. Siguiendo los vínculos que Heidegger establece entre el avenimiento de la técnica y la transformación de la escritura analizamos su noción de serenidad para contraponerla al modo en que Friedrich Nietzsche, Walter Benjamin y Michel Foucault se sirven de distintos objetos técnicos para generar nuevas formas de pensamiento y de escritura.

Palabras clave: Pensamiento, Escritura, Heidegger, Nietzsche, Benjamin, Foucault.

\begin{abstract}
This article examines the relationships between writing, technique and thinking. Martin Heidegger's reflections on why "science don't think" allow us to examine the problem of the homogenization of thought and writing in contemporary universities. To indicate today that «academy don't think» invites us to reflect on these prevailing modes of thought and writing. Following the links that Heidegger establishes between the compromise of the technique and the transformation of the writing we analyze his notion of serenity to oppose it to the way in which Friedrich Nietzsche, Walter Benjamin and Michel Foucault use different technical objects to generate new ways of thinking and writing.
\end{abstract}

Keywords: Thinking, Writing, Heidegger, Nietzsche, Benjamin, Foucault.

La universidad contemporánea parece haberle declarado la guerra al libro. El mismo objeto que, a partir de la invención de la imprenta y la expansión de las universidades y las bibliotecas se convirtió en el emblema cultural del humanismo y el acceso al conocimiento, ha pasado a ser el gran segundón de las evaluaciones que marcan el modo, ritmo y forma de la 


\section{Ester Jordana Lluch}

academia contemporánea. El «paper» y las revistas indexadas se han erigido como el modo hegemónico y homogéneo de compartir resultados de investigación y conocimiento en todas las disciplinas. En el seno de una universidad neoliberal totalmente alejada de los viejos valores humanistas, la investigación y el conocimiento se han convertido en un jugoso negocio para los grandes emporios editoriales que sustentan las revistas indexadas de referencia mundial.

Nuestro propósito es reflexionar sobre la transformación de la escritura en la universidad situando el foco de análisis en la relación entre técnica y escritura. Lejos de establecer una inane contraposición entre el libro y el «paper» (situando el libro como objeto paradigmático del paraíso perdido del pensamiento humanista) vamos a examinar de modo transversal la relación entre escritura y técnica atendiendo a una doble dimensión: el despliegue de la escritura «técnica» en el medio académico y el despliegue de la «técnica» en relación con la escritura. Tomando como punto de partida las reflexiones de Heidegger en torno a los vínculos entre técnica, pensamiento y escritura mostraremos cómo Heidegger, Nietzsche, Benjamin y Foucault exploraron en sus trabajos distintas formas de subversión de la escritura «técnica» del libro académico.

\section{La academia no piensa}

En el último curso que impartió en la Universidad de Friburgo Heidegger pronunció una frase aparentemente controvertida: «la ciencia no piensa». Decimos que tan solo es controvertida aparentemente porque, como veremos, esa afirmación cobra sentido en el seno de la caracterización heideggeriana del pensamiento. Heidegger presentó ese diagnóstico de este modo:

"El fundamento de este estado de cosas estriba en que la ciencia no piensa. No piensa, porque según su manera peculiar de proceder y de sus medios, nunca sabe pensar --es decir, pensar según la manera del pensador. Que la ciencia no sabe pensar, no es ningún defecto, sino una ventaja. Sólo eso le asegura la posibilidad de acceso a una determinada región de objetos, según el modo de la investigación, y que se establezca en ella” (Heidegger, 1997: 258). 


\section{Ester Jordana Lluch}

La afirmación de que la ciencia no piensa remite, pues, a la exigencia heideggeriana de un pensamiento que opere más allá de la metafísica de la presencia y pueda pensar de nuevo el ser: es necesario pensar lo impensado, esto es, el origen esencial del ser del ente. Ese diagnóstico se articula, en los años cincuenta, con las reflexiones en torno a la técnica en las que contrapone el pensar calculante propio de la era de la técnica a un pensar meditativo ajeno al pensamiento científico (Acevedo, 2010).

Como expone en «Ciencia y Meditación», Heidegger sitúa como carácter distintivo de la ciencia moderna postularse como «teoría acerca de lo real» desde la concepción de lo real como lo mensurable y calculable. Esto no significa, aclara el autor, identificar esa noción de cálculo con «el sentido estrecho de operar con números»:

“Calcular, en un sentido amplio y esencial, significa: esperar una cosa, es decir, tenerla en consideración, contar con algo, esto es, poner nuestra expectativa en ello. De ese modo, toda objetivación de lo real es calcular, ya sea persiguiendo los efectos de las causas, que aclara causalmente, ya haciéndose imágenes morfológicamente sobre los objetos, ya asegurando en sus fundamentos conexiones de secuencia y de orden" (Heidegger, 1997: 165).

En tanto que el conocimiento se relaciona con el mundo a partir de identificar el pensar con pensar un determinado dominio de objetos, la especialización constituye, señala el autor, una consecuencia necesaria, pero también positiva, de la ciencia moderna. Ahora bien, el problema es considerar ese pensar calculante como la única forma de pensamiento posible en tanto que ese modo de pensar, vinculado al despliegue de la técnica, dispone una determinada relación con el mundo. En la estela de las reflexiones efectuadas dos años antes en su conferencia «La pregunta por la técnica», Heidegger señala que lo inquietante del mundo técnico en que estamos es nuestra incapacidad de «enfrentar meditativamente lo que propiamente se avecina en esta época». Es necesario, pues, poner en juego «el pensar meditativo frente al pensar meramente calculador» (Heidegger, 2002: 26). 


\section{Ester Jordana Lluch}

Esa disposición del mundo es lo que Heidegger caracteriza como Gestell. La pregunta por la técnica nos revela así el modo en que el mundo se ha convertido, para el pensamiento occidental, en recurso. Si bien esa pregunta va de la mano del desarrollo de la técnica moderna, para Heidegger, la pregunta por la técnica es una pregunta ontológica. No se trata de negar ese mundo técnico que nos rodea sino, por el contrario, de poder pensarlo antes de que el modo técnico de pensar y habitar el mundo como disposición impida que podamos pensar esa relación velando para siempre la posibilidad de pensar el Ser más allá del ente. Aquello que la ciencia no puede pensar es, por tanto, el modo en que el mundo ha sido concebido para ser conocido a partir de esa disposición de dominios de objetos distintos. La objetividad de la naturaleza, dirá, «es ya y de antemano solo un modo en el que se expone la naturaleza (Heidegger, 1997: 170).

Heidegger contrapone a ese pensar calculador el pensar meditativo: un pensar que piensa «en pos del sentido que impera en todo cuanto es»(Heidegger,2002: 19). Tan solo al meditar sobre el estatuto contemporáneo del propio pensamiento puede afirmarse que aquello que caracteriza el mundo contemporáneo es una falta de pensamiento. Ese pensamiento meditativo, señala Heidegger, «se da tan poco espontáneamente como el pensar calculador», «exige a veces un esfuerzo superior», «exige un largo entrenamiento» (Heidegger, 2002: 19).

En la alocución pronunciada el 30 de octubre de 1955 publicada bajo el título «Serenidad», Heidegger afirmaba que la época moderna podía caracterizarse por la falta de pensamiento atendiendo a los rasgos que caracterizan la investigación:

"Su peculiaridad consiste en que cuando planificamos, investigamos, organizarnos una empresa, contamos ya- siempre con circunstancias dadas. Las tomamos en cuenta con la calculada intención de unas finalidades determinadas. Contamos de antemano con determinados resultados. Este cálculo caracteriza a todo pensar planificador e investigador. Semejante pensar sigue siendo cálculo aun cuando no opere con números ni ponga en movimiento máquinas de sumar ni calculadoras electrónicas" (Heidegger,2002: 18). 
Ester Jordana Lluch

Cualquiera que haya participado de una convocatoria de investigación en la universidad contemporánea habrá identificado, en la descripción que hacía Heidegger, ese modo de concebir la investigación como un proyecto cuyos resultados deben y pueden anticiparse de antemano. Los proyectos de investigación exigen hoy anticipar logros, calibrar su impacto tanto en términos de producción (congresos, artículos, publicaciones, etc.) como de retorno social (utilidad, aplicación, transferencia, etc.).

Ese pensamiento cuantificador que, para Heidegger, caracterizaba la ciencia moderna se ha convertido, en las últimas décadas, en el modo de pensar propio de la academia en un sentido amplio. La cuantificación ha desplazado su posición en relación al mundo para inscribirse en el seno de las relaciones pedagógicas y de investigación: cuantificación de la calidad docente a través de la evaluación de sus resultados; cuantificación de la producción en investigación a través del número de publicaciones en revistas indexadas; cuantificación de la actividad investigadora y docente a partir de las acreditaciones y las evaluaciones externas; de las instituciones a partir de rankings mundiales, etc. Pero también se ha inscrito en la relación entre pensamiento e investigación en el sentido más profundo que apuntaba Heidegger: configurando el tiempo como proyecto, situando una permanente relación de causas y efectos, de objetivos y retos en cada acción que emprendemos en el presente. Una proyección estructurada a partir de una secuencia discreta y continua de objetivos que es monitorizada por una evaluación constante de resultados que deriva en consecuencias meritorias o punitivas: a menos productividad menos financiación, más carga de trabajo, más gestión, etc.

Si en algún momento la Universidad pudo acoger no solo a investigadores y científicos sino también a pensadores, hoy el pensamiento y la investigación cuantitativa se han impuesto: no cabe otro modo de pensar. La academia contemporánea, imaginamos, sería para Heidegger la consumación de ese pensamiento calculador que expulsa al pensamiento meditativo. Si Heidegger señalaba que en base a ese pensamiento cuantificador podía afirmarse que «la ciencia no piensa», quizás hoy nos diría, a partir de la imposición y la extensión de ese pensamiento cuantificador como la forma homogénea de concebir cualquier forma de conocimiento o investigación, que la academia no piensa. 


\section{Ester Jordana Lluch}

\section{Técnica y escritura}

El despliegue de la técnica, como indicábamos, es concebido por Heidegger como un acontecimiento ontológico en el seno del cual se oculta la relación entre pensamiento y ser. En ese proceso, la irrupción de la técnica en la escritura tendrá consecuencias determinantes. En el Parménides, Heidegger identificaba ese dominio de la técnica en relación a la escritura misma a través del paso de la escritura a mano a la escritura mediante la máquina de escribir. Para Heidegger, el origen de la esencia de la escritura es esa relación con la mano que, al transferirse a la máquina, genera una «transformación en la relación del ser con el hombre» (Heidegger, 2005: 111). La aparición de la escritura maquínica es leída como una homogenización de lo humano y, al mismo tiempo, como una modificación en el ser mismo del lenguaje al convertir la palabra en «comunicación»:

"La máquina de escribir arranca la escritura del dominio esencial de la mano, es decir, del dominio de la palabra. Esta misma se convierte en algo «mecanografiado». [...] La escritura maquinal despoja a la mano de su rango en el dominio de la palabra escrita y degrada la palabra a un medio de comunicación. Además, la máquina de escribir ofrece la «ventaja» de ocultar el manuscrito y, con ello, el carácter. En la máquina de escribir todos los hombres tienen el mismo aspecto" (Heidegger, 2005: 105)

Como vemos, para Heidegger, la transformación de la escritura a través de la técnica no remite simplemente a un mero uso instrumental de la máquina de escribir como objeto técnico: modifica la relación entre pensamiento y escritura convirtiendo la palabra en comunicación. Desde esa perspectiva, el diagnóstico heideggeriano permite poner en relación el auge comunicacional de la palabra que caracteriza la época moderna con el despliegue del pensamiento calculador propio de la tecnificación de nuestra relación con el mundo. Por tanto, la relación entre técnica y escritura despliega en Heidegger una doble dimensión inseparable: la 


\section{Ester Jordana Lluch}

escisión de la mano y la escritura a partir de la mecanización técnica de la escritura (máquina de escribir, ordenador, etc.) configura el lenguaje como comunicación en un sentido ontológico.

La cuestión, para Heidegger, no es dejar de relacionarnos con esos objetos técnicos sino preguntarnos cómo relacionarnos con unos objetos técnicos que no dejan de intensificar nuestra servidumbre. Heidegger señalará que podemos decir al mismo tiempo «sí» a su uso y «no» a que anulen nuestra esencia, esto es, nuestra capacidad de pensar el Ser:

"Para todos nosotros, las instalaciones, aparatos y máquinas del mundo técnico son hoy indispensables, para unos en mayor y para otros en menor medida. Sería necio arremeter ciegamente contra el mundo técnico. Sería miope querer condenar el mundo técnico como obra del diablo. Dependemos de los objetos técnicos; nos desafían incluso a su constante perfeccionamiento. Sin darnos cuenta, sin embargo, nos encontramos tan atados a los objetos técnicos, que caemos en relación de servidumbre con ellos. Pero también podemos hacer otra cosa. Podemos usar los objetos técnicos, servirnos de ellos de forma apropiada, pero manteniéndonos a la vez tan libres de ellos que en todo momento podamos desembarazarnos (loslassen) de ellos. Podemos usar los objetos tal como deben ser aceptados. Pero podemos, al mismo tiempo, dejar que estos objetos descansen en sí, como algo que en lo más íntimo y propio de nosotros mismos no nos concierne. Podemos decir «sí» al inevitable uso de los objetos técnicos y podemos a la vez decirles «no» en la medida en que rehusamos que nos requieran de modo tan exclusivo, que dobleguen, confundan $\mathrm{y}$, finalmente, devasten nuestra esencia" (Heidegger, 1997: 27)

Heidegger señalará entonces que la actitud que caracteriza esa afirmación simultánea ante los objetos técnicos es la «serenidad (Gelassenheit) para con las cosas». Esa actitud de serenidad es la que nos permitirá dejar «de ver las cosas tan sólo desde una perspectiva técnica» 


\section{Ester Jordana Lluch}

abriendo la posibilidad de un «nuevo arraigo» que el mundo de la técnica destruye (Heidegger, 1997, 28-31).

Para Heidegger, lenguaje y pensamiento irán de la mano en su exploración de un pensar meditativo que pueda pensar el Ser a partir de la palabra, en particular, de la palabra poética. De ahí que esa «serenidad» acompañe no solo de una elaboración del pensamiento poético como forma de acceso al Ser, también la propia escritura heideggeriana despliega de forma performativa ese carácter pensativo. Por tanto, podemos ver cómo, para Heidegger, se establece una correspondencia entre modo de pensamiento y modo de escritura donde el pensar calculador y el advenimiento de la técnica derivarían en un lenguaje comunicacional al que cabe oponerle un pensamiento meditativo, una nueva actitud ante ese mundo técnico a través de la serenidad y una nueva relación con el lenguaje.

\section{Del «mamotreto» al «paper»}

La reflexión heideggeriana hace converger, como vemos, el advenimiento de la técnica concebida en sentido ontológico y la mecanización de la escritura en sentido histórico en el punto de inflexión que va a separar a la mano de la escritura, transformando el modo de ser del lenguaje mismo. Manteniendo esas dos dimensiones como ejes de reflexión nos proponemos, sin embargo, pensarlas de forma diferenciada. Por un lado, situando esa dimensión comunicacional del lenguaje como una práctica determinado modo de concebir y ejercer el lenguaje y, por otro, examinando los efectos de los distintos objetos técnicos en el marco histórico de las prácticas de escritura.

En el seno de la academia no han dejado de proliferar, a lo largo de su historia, una ingente cantidad de géneros de escritura. Géneros derivados del propio pensamiento académico concebido desde una suerte de lenguaje segundo que tiene como objetivo clarificar lo ya dicho, exponerlo de manera sencilla, resumir, simplificar, hacer eficiente la transmisión de un determinado contenido: manuales, monográficos, antologías, informes, reseñas, artículos, etc. Esos géneros académicos asumen, por tanto, unos rasgos y características diferenciales que fijan la forma que los define: el modo de estructurar el texto, el registro lingüístico utilizado, la posición de enunciación, los apartados que lo componen, etc. Tanto es así que, una vez esa forma 
La inservidumbre de la escritura en la época de la técnica: Heidegger, Nietzsche, Benjamin y Foucault

Ester Jordana Lluch

queda fijada, se podrá elaborar asimismo material didáctico para enseñar a escribir siguiendo todo ese conjunto de protocolos fijados.

En el libro de Calle de dirección única Walter Benjamin se hacía eco de una de las formas hegemónicas del pensamiento académico de la época: los libros destinados a mostrar la erudición del autor, compuestos de múltiples referencias y citas, elaboraciones conceptuales complejas, nociones ambiguas, etc. El texto se titula «Material didáctico»:

\section{"PRINCIPIOS DEL MAMOTRETO O EL ARTE DE FABRICAR LIBROS GRUESOS}

I, En toda la exposición deberán entreverarse continuas y prolijas referencias al plan de la obra.

II. Se introducirán términos para designar conceptos que, salvo en su definición misma, no vuelvan a aparecer en todo el libro.

III. Las distinciones conceptuales a las que con gran dificultad se llegue a lo largo del texto deberán desdibujarse de nuevo en las notas a los pasajes correspondientes.

IV. Se darán ejemplos para ilustrar conceptos que sólo sean tratados en su acepción general: así, donde se hable de máquinas, se enumerarán todos sus tipos.

V. Todo cuanto a priori esté claro de un objeto, será corroborado por una retahíla de ejemplos.

VI. Las correlaciones representables gráficamente serán descritas con palabras. En vez de dibujar, por ejemplo, un árbol genealógico, todos los vínculos de parentesco serán pormenorizados e ilustrados.

VII. Varios adversarios que defiendan la misma argumentación deberán ser refutados uno a uno. La producción media del erudito actual aspira a ser leída como un catálogo.

Pero ¿cuándo se llegarán a escribir libros como catálogos? Si, de esta suerte, la mala calidad del contenido aflora al exterior, nacerá una excelente obra 
La inservidumbre de la escritura en la época de la técnica: Heidegger, Nietzsche, Benjamin y Foucault

Ester Jordana Lluch

literaria en la que el valor de las opiniones vendrá indicado por una cifra, sin que por ello éstas sean puestas en venta. La máquina de escribir convertirá la mano del literato en algo extraño al portaplumas sólo cuando la precisión de las formas tipográficas intervenga directamente en la concepción de sus libros. Probablemente se necesiten entonces sistemas nuevos con caracteres tipográficos más variables. Y aquéllos sustituirán la escritura a mano por la inervación de los dedos que dan órdenes. Un período concebido métricamente, cuyo ritmo sea luego perturbado en un único punto, producirá la frase en prosa más bella que se pueda imaginar. Así, por una pequeña brecha abierta en el muro se filtra un rayo de luz en el gabinete del alquimista, haciendo destellar cristales, esferas y triángulos" (Benjamin, 1987: 39).

Frente a esos «mamotretos» descritos por Benjamin, donde la erudición se mediría por la capacidad de fabricar «libros gruesos», los «papers» de la academia contemporánea operan más bien a la inversa: no desde el rol del erudito sino del experto, no desde maximizar la extensión del texto sino desde la proliferación cuantitativa de textos breves, no desde largos desarrollos conceptuales sino desde el análisis de aspectos concretos. Marina Garcés (2013) caracteriza los efectos de esa nueva estandarización de la escritura en la academia contemporánea a partir de distintos ejes: la disociación de forma y contenido, de los conceptos o doctrinas de los distintos autores/as y sus formas de escritura; la imposición de la «voz» de experto que se dirige a otros expertos inherente al paper; el abandono de la escritura como experiencia de exploración e investigación; la instauración del paper como unidad de producción de la actividad investigadora que comporta la sumisión a sus formatos y protocolos para poder publicar, así como el imperativo de hacerlo; y la subordinación al inglés como lengua hegemónica de la producción académica universitaria.

Como vemos, del «mamotreto» heredero la institucionalidad universitaria forjada en el siglo XIX al «paper» de la universidad contemporáneo se precipita un profundo 


\section{Ester Jordana Lluch}

cambio en en la forma hegemónica del texto académico vinculada a una transformación en el modo de concebir la academia misma pero también a los modos de producción y reproducción técnica de la escritura. El «mamotreto» de Benjamin forma parte de una universidad concebida como salvaguarda de la tradición; de la erudición concebida como auctoritas en relación con esa herencia recibida; de un autor que, a imagen y semejanza del artista o el genio, se expresa en un "lenguaje otro" marcando una asimetría entre el autor erudito y el lector lego. Por tanto, el texto erudito debe ser largo y prolijo en desarrollos que nunca acaban de concretarse desposeyendo al lector de las herramientas necesarias para contrarrestar o refutar los planteamientos expuestos. El libro del erudito se concibe como un catálogo, dice Benjamin.

En el extremo opuesto, el «paper» contemporáneo opera, como señalaba Garcés, de experto a experto. Por tanto, se omite toda mediación o acceso a aquello de lo que se trata presuponiendo que el lector está familiarizado con el campo de conocimiento en cuestión. El objetivo es concentrar una aportación concreta a un campo de conocimiento que pueda exponerse y justificarse en apenas veinte páginas y que tan solo la comunidad experta (los revisores) podrá validar como una aportación legítima. La cita erudita desaparece para transformarse más bien en un acto judicial de reconocimientos cruzados de derechos de autor y de protección frente a cualquier acusación de plagio o apropiación indebida. La auctoritas concebida como la amplitud y profundidad adquiridas en un determinado campo de saber se convierte en la capacidad de mostrar una alta productividad cuantitativa cuya aportación al campo de saber experto queda avalada supuestamente por los propios mecanismos de selección inherentes a la publicación de artículos.

Sin embargo, en las dos formas textuales operan dimensiones comunes: por un lado, una dimensión comunicacional del lenguaje que, tal como analiza Jorge Larrosa, concibe «al profesor como un comunicador, o el hecho de entender la materia de estudio como un contenido» (Larrosa, 2019, p. 46). Por otro, la estandarización de una forma capaz de acoger a cualquier contenido a partir de todo un conjunto de parámetros técnicos: una estructura fijada, un tipo de enunciación, un registro linguiístico, un modo de relacionarse con otros conocimientos o otros textos, un propósito y un objetivo prefijados, la 
La inservidumbre de la escritura en la época de la técnica: Heidegger, Nietzsche, Benjamin y Foucault

Ester Jordana Lluch

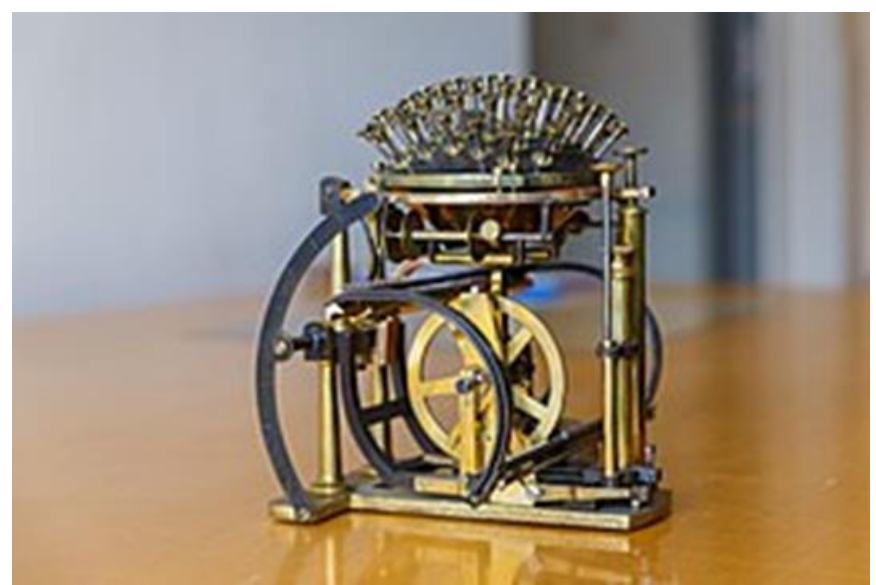

Licencia: Creative Commons AttributionShare Alike 4.0 International. Autor: Eremeev

posibilidad de evaluar y cuantificar la adecuación a esa forma prefigurada, etc. Aprender a escribir académicamente es, por tanto, aprender a ajustarse a esos requisitos técnicos: aprender a comunicar de manera clara y concisa, estructurar bien los textos, citar de manera adecuada, ajustar el contenido de aquello que quiere comunicarse a los límites prescritos, adecuar la tipografía, el tamaño, los márgenes, utilizar el registro adecuado, adoptar un lenguaje objetivo, etc. Todos esos requisitos técnicos definen una forna en la que cabe inscribir cualquier contenido de cualquier disciplina académica.

El «mamotreto» al que aludía Benjamin es correlativo a una erudición de herencia humanista y a la imprenta como técnica de reproducción mecánica de libros puestos al servicio de la universidad decimonónica en su tarea de nutrir las distintas disciplinas de saberes distintivos apoyados en la tradición precedente. El carácter técnico de esa escritura y su posibilidad didáctica (tal como exponía con ironía Bénjamin) remiten a esa estandarización efectuada por la academia. Por tanto, vamos a examinar cómo, frente a esa forma de escritura académica estandarizada, Friedrich Nietzsche, Walter Benjamin y Michel Foucault desarrollarán distintas estrategias para forjar nuevas relaciones entre pensamiento, técnica y escritura.

\section{Subvertir el «mamotreto»}

En el texto de Calle de dirección única que invocábamos anteriormente, Benjamin anunciaba dos posibilidades de subversión del «mamotreto». Por un lado, señalaba, si el libro erudito tendía al catálogo, era necesario explorar esa forma de composición. Por otro, si la máquina de escribir genera un extrañamiento respecto a la mano, las formas tipográficas podrán entrar a formar parte de la concepción de los libros. Por tanto, se 
La inservidumbre de la escritura en la época de la técnica: Heidegger, Nietzsche, Benjamin y Foucault

\title{
Ester Jordana Lluch
}

trataba de poner en relación la forma técnica que adoptaba la escritura con la técnica de escritura misma. Desde ahí, la máquina de escribir — lejos de constituir, como afirmaba Heidegger, un punto de inflexión en la relación entre pensamiento y lenguaje al separar la mano de la escritura - se convertía para Benjamin en una nueva condición de escritura que era necesario explorar. En una carta a Peter Gast, Nietzsche le escribía a su amigo algo que apunta en la misma dirección «nuestras herramientas de escritura también actúan sobre nuestros pensamientos» (citado por Kittler, 1999: 204).

A finales del siglo XIX competían en el mercado dos máquinas de escribir sustantivamente distintas. Hans Rasmus Johann Malling Hansen había desarrollado en Copenhague una curiosa máquina de escribir redonda a partir de observar cómo el lenguaje de signos de sus pacientes sordomudos era más rápido que el manual.

La disposición semiesférica tendría la ventaja de favorecer una disposición de la mano diferencial que permitiría a las personas ciegas orientarse fácilmente con el tacto. Por tanto, la «bola de escribir» inventada por Rasmus Malling-Hansen (que fue comercializada en Europa) potenciaba, sobre todo, la rapidez de la escritura mecánica frente a la manual. Por otro lado, la empresa americana de máquinas de coser, Remington and Sons había comprado una patente a partir de la cual pronto incorporaron la posibilidad de ver frontalmente lo que se estaba escribiendo y acabaron imponiéndose en el mercado.

Cuenta Friedrich Kittler en su libro Gramophone, Film, Typewriter (1999) que, a raíz de su creciente ceguera, Nietzsche se puso en contacto con Malling-Hansen interesándose por su máquina de escribir al ser más ligera que la americana. Su condición nómada vinculada a su enfermedad requería de una máquina de escritura fuese también una compañera de viaje. Una semana después de practicar con ella, Nietzsche escribiría: «los ojos ya no tienen que hacer su trabajo». Llegó incluso a escribirle un poema que Kittler cita en su libro (1999, 2017):

\author{
“THE WRITING BALL IS A THING LIKE ME: MADE OF IRON \\ YET EASILY TWISTED ON JOURNEYS \\ PATIENCE AND TACT ARE REQUIRED IN ABUNDANCE, \\ AS WELL AS FINE FINGERS, TO USE US"
}




\section{Ester Jordana Lluch}

Resulta interesante, pues, considerar la introducción de la máquina de escribir no tanto como una pérdida de la relación mano-ojo, tal como la consideraba Heidegger, como de una nueva relación mano-ojo que configura nuevas condiciones materiales. Kittler apunta en esa dirección al mostrar cómo la máquina de escribir desarticulará la relación entre autoría y autoridad ejercida patriarcalmente a través de la escritura:

"Significantly enough, the invention was aimed primarily at educated but unfortunately blind fathers for the purpose of illuminating their morally blind sons with letters and epistolary truths. [...] The "writing-machine," in that sense, only brought to light the rules regulating discourses during the age of Goethe: authority and authorship, handwriting and rereading, the narcissism of creation and reader obedience. The device for "everybody" forgot women. (Kittler, 1999: 188)

Para Kitller, la escritura de Nietzsche habría estado, pues, profundamente condicionada por las condiciones materiales vinculadas a la adquisición de su máquina de escribir. Lejos de un mero instrumento que habría hecho de nuevo posible la escritura, afirma el autor, la modificó profundamente al cambiar los argumentos, los pensamientos y el estilo retórico por aforismos, juegos de palabras y un estilo telegráfico:

"Nietzsche, as proud of the publication of his mechanization as any philosopher, changed from arguments to aphorisms, from thoughts to puns, from rhetoric to telegram style. That is precisely what is meant by the sentence that our writing tools are also working on our thoughts. Malling Hansen's writing ball, with its operating difficulties, made Nietzsche into a laconic.” (Kittler, 1999: 203)

El «mamotreto» erudito se descompondría, pues, a partir de una escritura que piensa materialmente desde su condición de escritura mecánica. La imposición de un pensamiento erudito que se concibe como un hilo de continuidad a través de cientos de páginas se descompone 


\section{Ester Jordana Lluch}

en favor de nuevas posibilidades: el fragmento como una unidad de pensamiento en sí misma (los aforismos nietzscheanos) o el fragmento concebido como una unidad de composición que establece distintos tipos de relación con otros fragmentos, esto es, el fragmento como montaje. Como es sobradamente conocido, esa será la estrategia de Benjamin. Las distintas formas de montaje que se despliegan diversas formas artísticas (el montaje-collage dadaísta o surrealista, el montaje teatral brechtiano, el montaje cinematográfico de las vanguardias rusas) configuran nuevos modos de generar pensamiento en la época de la reproductibilidad técnica del arte que Benjamin explorará filosóficamente a través de la escritura. Desde ahí, Benjamin llegará hasta el extremo opuesto de esa relación técnica y comunicacional del lenguaje que neutraliza la forma en virtud del contenido afirmando un lenguaje que ya no expresa sino que muestra:

"Método de este trabajo: montaje literario. Yo no tengo nada que decir. Sólo que mostrar. No voy a hurtar nada valiosos ni me apropiaré de formulaciones ingeniosas. Pero los andrajos, los desechos: ésos no los voy a inventariar, sino hacerles justicia del único modo posible: usándolos" (Benjamin, 2005: 462)

Si Nietzsche hacía del aforismo la impugnación del «mamotreto» en términos de una nueva forma de escritura breve y fragmentaria Benjamin hará lo propio con la autoridad de la cita erudita. En Calle de dirección única, en el fragmento titulado «Quincallas», afirma: «En mi trabajo las citas son como salteadores de caminos que irrumpen armados y despojan de su convicción al ocioso paseante» (Benjamin, 1987: 85). Esa frase será retomada tanto por Theodor W. Adorno como por Hannah Arendt en sus respectivos ensayos sobre Benjamin. Para Adorno, el uso de las citas remitiría a una técnica de montaje que tendría como objetivo eliminar toda interpretación del autor en relación con los textos para que los significados aparezcan mediante el montaje mismo de los fragmentos ${ }^{1}$ :

\footnotetext{
${ }^{1}$ Rolf Tiedemann, editor tanto del ensayo de Adorno sobre Benjamin como del Libro de los pasajes considera, sin embargo, que el plan de Benjamin no era, como señala Adorno, el de componer meramente las citas sin ninguna interpretación sino componerlas también con lo que Benjamin denominaba la «interpretación de las singularidades» (Tiedemann en Benjamin, 2005: 887).
} 
Ester Jordana Lluch

"La intención de Benjamín era renunciar a toda interpretación manifiesta y hacer surgir los significados únicamente mediante el montaje chocante del material. La Filosofía no sólo debía recoger el surrealismo, sino ser surrealista ella misma. Entendía literalmente la frase de Dirección única de que las citas de sus trabajos eran como ladrones en el camino, que saltan de pronto y le arrancan al lector sus convicciones. Como coronación de su antisubjetivismo, la obra principal solamente debía consistir en citas" (Adorno, 1995: 24).

Arendt, por su lado, enfatizaba ese uso de las citas en relación con una ruptura con el pasado y la tradición que Benjamin convierte en un nuevo modo de tratar con el pasado:

"Hasta donde el pasado ha sido transmitido como tradición, posee autoridad; hasta donde la autoridad se presenta desde un punto de vista histórico, se convierte en tradición. Walter Benjamín sabía que la ruptura en la tradición y la pérdida de autoridad que se dio en su vida eran irreparables y llegó a la conclusión de que tenía que descubrir nuevas formas de tratar con el pasado." (Arendt, 1990: 178).

Arendt señala que el «descubrimiento de la función moderna de las citas» por parte de Benjamin surgió de la desesperación ante el propio presente y «el deseo de destruirlo», en relación con ese uso de las citas. Así, frente a la erudición de la cita que impulsa la auctoritas a través de una tradición que se impone al presente, esos «fragmentos de pensamiento» dirá Arendt, tendrán como objeto una doble tarea: «interrumpir el flujo de la presentación» y «concentrar dentro de ellas aquello que se presenta» (Arendt, 1990: 79). De ese modo, señala Arendt, su propia biblioteca — fruto de la gran pasión de Benjamin por el coleccionismo — se irá transformando en una colección de citas.

Por tanto, vemos cómo, con Nietzsche y Benjamin, el «mamotreto» es subvertido desde dentro, tanto a partir de un nuevo modo de escritura fragmentaria (el aforismo), como a partir de la 


\section{Ester Jordana Lluch}

descomposición material del texto en fragmentos (citas) que no solo impugnan la autoridad del pasado sobre el presente sino que irrumpen en el mismo abriendo nuevas posibilidades. La cita abandona así su carácter de autoridad en sentido estricto (autoridad académica) para convertirse en la pieza de un elemento de montaje con potencial disruptivo y transformador.

La Biblioteca, que para Benjamin encarnaba a nivel individual ese afán coleccionista que desposee a los objetos de su valor de uso y su valor de cambio, no deja de ser, sin embargo, el lugar de culto de los «mamotretos» por excelencia, el lugar donde se acumulan y se reverencian en tanto que objetos eruditos. De forma similar a Benjamin, Foucault convertirá el pasado en el contrapunto que permite inquietar el propio presente. Sin embargo, su modo de subvertir la auctoritas inherente a la erudición de los libros-mamotreto será distinta a la de Benjamin. No se tratará tanto de descomponerlos en citas bajo una mirada miope que atiende al fragmento y luego genera efectos de composición al «mostrar» a través del montaje sino bajo una mirada hipermétrope que desenfoca las autorías de los lomos de los libros de un determinado estante de la biblioteca para interrogar las formas de interrelación que se traman entre sus modos de pensar y escribir. Un gesto antiautoritario que confronta la erudición como posición asimétrica y jerárquica y que está contenido tanto en la arqueología como en la genealogía como formas de intervenir la Biblioteca para convertirla en Archivo.

Convertir la Biblioteca en Archivo comporta, en primer lugar, dejar de concebir la Biblioteca como heredera de la salvaguarda de la tradición concebida como un espacio de recogimiento para un lector que, en silencio, acoge y venera la auctoritas desplegada en los «mamotretos» eruditos. Al convertir la Biblioteca en Archivo, la auctoritas desaparece como figura de autoridad, los libros en las estanterías dejan de constituir unidades monádicas yuxtapuestas según un determinado criterio de ordenación en el espacio físico para convertirse en documentos que se entrelazan. El autor pierde su condición jerárquica para inscribirse en formas de pensamiento, conceptos y nociones compartidas históricamente. Bajo esa ficción de orden que constituye todo archivo, Foucault opera buscando sincronías, efectuando una lectura comparativa de conceptos, nociones, modos de ordenar y clasificar el conocimiento compartidos más allá de los autores. El Archivo, definido como «el sistema general de la formación y la transformación de los enunciados» (Foucault, 2005: 71) subvierte la Biblioteca como espacio de preservación y 


\section{Ester Jordana Lluch}

transmisión de la tradición erudita. El Archivo, como la cita en Benjamin, transforma nuestra relación con la autoridad del pasado tanto en términos de un relato impuesto al propio presente como de un relato del que tan solo son agentes y protagonistas aquellos nombres propios que las Bibliotecas sitúan en un lugar distintivo.

La Biblioteca como paradigma de la tradición, de la acumulación erudita de libros consignados por autores y ordenados cronológicamente en el espacio es subvertida por el archivo a través del gesto que convierte esos mismos libros y disposición espacial en un modo de pensar entre y a través de ellos. Las estanterías dejan de ser meros soportes de clasificación de los libros organizados en un espacio físico para convertirse en objetos-límite de esas formas de escritura y pensamiento. El gesto aparece tímidamente en Historia de la locura y se repite explícitamente al inicio de El nacimiento de la clínica y de Vigilar y Castigar: tomar dos libros, a un extremo y otro del largo estante que ordena un determinado periodo contraponiéndolos para mostrar el abismo que los separa. En «Defender la sociedad», haciendo balance de las investigaciones expuestas hasta entonces en el Collège de France, Foucault señalaba:

"Después de todo, el hecho de que el trabajo que les presenté haya tenido ese aspecto a la vez fragmentario, repetitivo y discontinuo correspondería con claridad a algo que podríamos llamar una - pereza febrill, la que afecta el carácter de los enamorados de las bibliotecas, los documentos, las referencias, las escrituras polvorientas, los textos que jamás se leen, los libros que, apenas impresos, se cierran y duermen luego en anaqueles de los que sólo son sacados siglos después. [...] Esto convendría a quienes se sienten solidarios con una de las sociedades secretas sin duda más antiguas y también más características de Occidente [...] Me refiero a la grande, tierna y cálida francmasonería de la erudición inútil” (Foucault, 2001: 18).

Frente a esa «erudición inútil» Foucault sitúa ese trabajo de Biblioteca en el marco de un conjunto de impulsos críticos caracterizados justamente por la «eficacia de las ofensivas dispersas y discontinuas», el despliegue de un «carácter local de la crítica» frente a teorías 


\section{Ester Jordana Lluch}

globales y generales. Una crítica efectuada a partir de «retornos de saber» concebidos, en primer lugar, como el gesto de desenmascarar saberes históricos que habían quedado de algún modo atrapados «dentro de los conjuntos funcionales y sistemáticos, y que la crítica pudo hacer reaparecer por medio, desde luego, de la erudición»y, en segundo lugar, por restituir saberes que habían quedado descalificados, «saberes jerárquicamente inferiores, saberes por debajo del nivel del conocimiento o de la cientificidad exigidos» Ese «acoplamiento entre los saberes enterrados de la erudición y los saberes descalificados por la jerarquía de los conocimientos de las ciencias» impulsó esa crítica concreta, situada, una crítica que emerge de las luchas, de las memorias enterradas de los combates (Foucault, 2001:18-24).. Esa forma de crítica permite articular conjuntamente la arqueología y la genealogía:

"la arqueología sería el método propio del análisis de las discursividades locales, y la genealogía, la táctica que, a partir de esas discursividades locales así descriptas, pone en juego los saberes liberados del sometimiento que se desprenden de ellas" (Foucault, 2001: 24).

Llegamos, pues, al final de nuestro recorrido. Retomando nuestra inquietud inicial en torno a la academia contemporánea y sus formas de escritura, hemos tratado de plantear cómo la estandarización académica de las formas de pensamiento y escritura que se configuran en el seno de la universidad pueden ser analizadas históricamente. La relación entre técnica y escritura nos ha mostrado que, si bien podemos analizar cómo fijar una determinada forma de escritura comporta, fijar también un modo de pensamiento que «no piensa», su condición histórica permite subvertirla. De distintos modos, hemos visto cómo Heidegger, Nietzsche, Benjamin o Foucault han planteado formas de subversión a esa escritura, bien en términos ontológicos (Heidegger) bien en términos históricos a partir de subvertir la forma en que esa escritura académica fija determinados condicionantes técnicos. La pregunta es, por tanto, qué estrategias pueden dar lugar hoy a la disrupción de la forma de homogenización del pensamiento a través de la escritura que comporta el formato «paper» en la universidad contemporánea. Esa misma forma de escritura que no hemos dejado de ejercer en estas líneas. 
La inservidumbre de la escritura en la época de la técnica: Heidegger, Nietzsche, Benjamin y Foucault

\section{Ester Jordana Lluch}

\section{Bibliografía}

Acevedo, J. (2010). «La frase de Heidegger «la ciencia no piensa», en el contexto de su meditación sobre la era técnica». Revista de Filosofía. Volumen 66, 5-23.

Adorno, T. (1995). Sobre Walter Benjamin. Madrid, España: Cátedra.

Arendt, H. (1990). «Walter Benjamín. 1892-1940». En: Hombres en tiempos de oscuridad. Barcelona, España: Gedisa, p. 139-192.

Benjamin, W. (1987). Dirección única. Madrid, España: Alfaguara.

Benjamin, W. (2005). Libro de los pasajes. Madrid, España: Akal.

Foucault, M. (2005). La Arqueología del saber. Madrid: Siglo Veintiuno.

Foucault, M. (2001) Defender la sociedad. Curso en el Collège de France (1975-1976). Buenos Aires, Argentina: FCE.

Garcés, M. (2013). «La estandarización de la escritura. La asfixia del pensamiento filosófico en la academia actual», Athenea Digital: revista de pensamiento e investigación social,13, (1), p. 29-41.

Heidegger, M. (2002). «Serenidad», En: Serenidad. Barcelona, España: Ediciones del Serbal, p. 13-32.

Heidegger, M. (2005). Parménides. Traducción Carlos Másmela. Madrid, España: Akal,

Heidegger, M. (1997). Filosofía, Ciencia y Técnica. Santiago de Chile, Chile: Editorial Universitaria.

Kittler, F. A. (1999). Gramophone, Film, Typewriter. Stanford: Stanford University Press.

Larrosa, J. (2019. P de Profesor. Buenos Aires, Argentin: Noveduc.

León-Casero, J.; Castejón, J. M. (2020) «Mal de archivo. Disciplina y biopolítica del diseño de bibliotecas en la arquitectura contemporánea». Arte, Individuo y Sociedad 32(1),155-172.

Mascaro, L. (2020) «La máquina de escribir de Heidegger: los objetos técnicos como ejemplos en su filosofía», Pensando. Revista de Filosofía Vol. 11, №24

Tello, A. M. (2018). Anarchivismo. Tecnologías políticas del archivo. Buenos Aires, Argentina: La Cebra. 